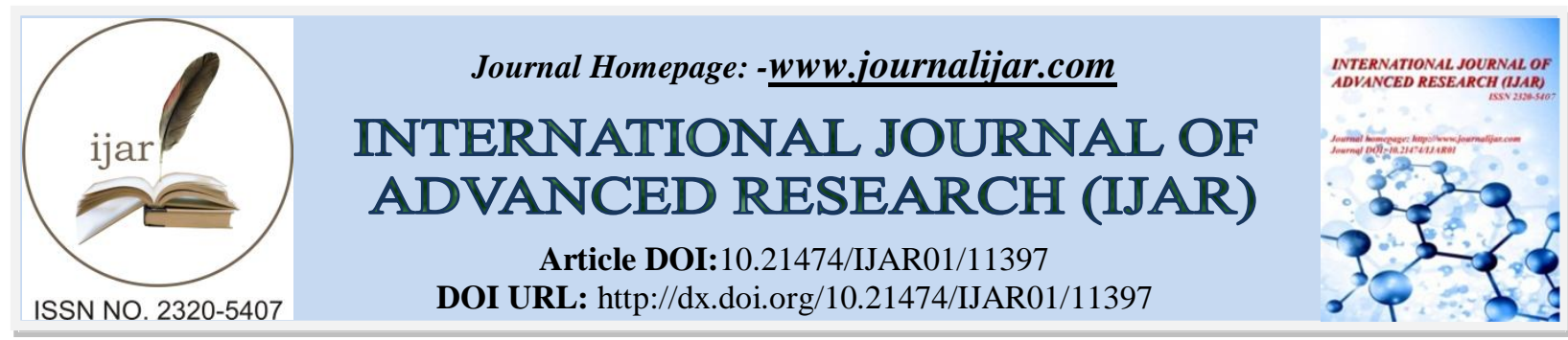

RESEARCH ARTICLE

\title{
MEASUREMENT OF QUALITY OF LIFE IN POST MENOPAUSAL WOMEN IN INDIA -A SYSTEMATIC REVIEW
}

\section{Suketi Rajhansa ${ }^{1}$ and Neeraj Kumar ${ }^{2}$}

1. Intern, Dr. APJ Abdul Kalam College of Physiotherapy, Pravara Institute of Medical Sciences (Deemed to be University), Loni, Ahmednagar, India.

2. Officiating Professor and HoD, Department of Orthopaedic Physiotherapy, Dr. APJ Abdul Kalam College of Physiotherapy, Pravara Institute of Medical Sciences (Deemed to be University), Loni, Ahmednagar, India.

\section{Manuscript Info}

Manuscript History

Received: 25 May 2020

Final Accepted: 28 June 2020

Published: July 2020

Key words:-

Assessment, Quality of Life, Post-

Menopausal Women, India, MENQOL

\section{Abstract}

Background: Quality of life has important impact on the life. Women go through some of the transition in their non reproductive years of life to assess the quality of life and factors having impact on them are scored according to MENQOL in Indian women population.

Methodology: A systematic review was conducted by selecting the articles for review from Goggle scholar using the keywords assessment, menopause, quality of life, post menopause, India, MENQOL. The time frame of the search was from 2010 to 2020 to focus on instrument MEQOL which is used to measure quality of life. After each database was searched by inclusion, reference of relative database was searched for further use of MENQOL scale and paper reporting. An Internet search was also conducted to retrieve literature not available through usual databases. It was accomplished by combining psychometric terms (i.e., reliability, validity). Using the keywords articles were found on the internet

Result: The average percentage of each domain of all the 12 studied

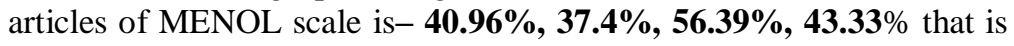
vasomotor, psychological, physical and sexual respectively

Conclusion: The study concluded that after comparing 12 studies and their scoring of MENQOL in Indian population physical domain is more affected than vasomotor, psychological or sexual. 


\section{Introduction:-}

Menopause is that the end of a woman's menstrual cycles. The term can describe any of changes women bear just before or after women stop having menstrual cycle, making end of your reproductive years. Menopause could be a universal event in midlife of a women occurring around the age of 50 years in most developed countries. ${ }^{1}$ Menopause is that the permanent cessation of menstruation due to loss of ovarian follicular function. Clinically, menopause is detected after 12 months of amenorrhea, that the time of the ultimate menses is set looking back. The common age at menopause is about 51 years. ${ }^{2}$ The physiology and clinical presentations of perimenopause are not well understood, but one model proposes that it occurs little by little. Early perimenopause occurs when the neurohormonal systems that rule ovulation begin to become dysregulated, without evidence of obvious modifications in cycle length. Middle to late perimenopause is also characterized by irregular menstrual cycles, particularly by short cycles intermingled with longer time between menstruation. ${ }^{2}$ With increased long life, women spend about one third of their life within the postmenopausal period. Menopause is followed by endocrine, physical, and mental disorders and might last for quite a few years. Although these symptoms and problems are frequent, nobody experiences all of them. However, it is predictable that $75 \%$ of postmenopausal women experience severe symptoms, number of which cause extreme discomfort and life disruption ${ }^{3}$

A woman is born with eggs, which are stored in ovaries. Ovaries secret the hormones estrogen and progesterone which are responsible for women's menstruation and process of releasing egg called ovulation. Menopause results when the ovaries stop releasing an egg every month and menstruation stops ${ }^{4}$

Regular part of aging is menopause if it happens after the age of 40. Some women can go through menopause early as a result of surgeries like removal of ovaries named as hysterectomy or damage to ovaries from chemotherapy. If this happens before age 40 for any reason it's called premature menopause. ${ }^{5}$

Natural menopause is not caused by any medical or surgical process it's a slow process and has threestages ${ }^{6}$ 1) Pre-menopause - This phase begins many years before menopause. When ovaries start secreting less amount of estrogen. This phase lasts until menopause exactly the point at which your ovaries stop releasing eggs. Last 1 to 2 years of pre-menopause level of estrogen falls faster.

2) Menopause - This phase begins when it been year when women had menstrual cycle. Ovaries finally stops releasing eggs and making estrogen

3) Post- menopause - These are some of the years after menopause. Symptoms of menopause like hot flushes usually ese.

\section{Women's quality of life:}

(QoL) is additionally obstructed by adverse physical and psychological changes women passes through during the menstrual change. ${ }^{5}$ These changes associated with menopause may affect a woman's quality of life ${ }^{.5}$ About, $50 \%$ to $80 \%$ of population complain of menopausal symptoms such as hot flashing, sweating, sleep disturbance, tiredness, and depression. These symptoms are in charge for the quality of life (QOL). Per globe Health Organization (WHO), QOL is defined as individual's perception of their situation within the background of the culture and rate systems during which they live and in relevancy to their goals. ${ }^{7}$

\section{Importance of health care:}

The health care needs of women should be measured on the basis of a multidimensional assessment of their mental, physical and social well-being. Only a multidisciplinary approach permits an assessment of health care needs and the provision of effective care. Several constraints prevent an offer of preventive medicine to the entire older population in order to avoid at least the major causes of disability, morbidity and mortality. Nevertheless, it would desirable to offer at least health counseling and screening tests for cardiovascular disease, cancer and osteoporosis to women encountered in daily clinical practice. At the minimal level, prevention programs should be targeted at women with high risk factors for the above diseases. International public health agencies and health professionals should join efforts to develop strategies to provide elderly women with the best health care. Recommendations and guidelines on how to prevent the major causes of morbidity, disability and mortality are necessary. In addition, it is also necessary that health care professionals and the female population know and follow these guidelines and recommendations. Health care professionals should also be encouraged to commit themselves to practicing 
preventive medicine even in the elderly, in order to avoid the burden of disease that women aged 66 and above and the entire society, have to suffer ${ }^{8}$

\section{Menopause-Specific QOL:}

questionnaire for measuring the QOL in postmenopausal women. This questionnaire consists of 29 items. In vasomotor consist of 3 items, psychosocial consists of 7 items, physical consist of 16 items and sexual consists of 3items. Validity and reliability tests for this questionnaire were absorbed in Iran. During this study, test-retest (intraclass correlation coefficients) was used for the MENQOL questionnaire reliability. Scoring of MENQOL questionnaire were $0.93,0.88,0.87$, and 0.92 for the physical, psychological, sexual and vasomotor domains, respectively. ${ }^{7}$

\section{MENQOL:}

questionnaire has seven-point Likert scale and ranges from 0 to 7. A "zero" is equal to a woman answering "no", showing she has not experienced this symptom in the past month. Score "one" shows that the woman experienced the symptom, but it was not trouble at all. Scores "two" to "seven" show growing levels of bother experienced from the symptom and correspond to " 1 " through " 6 " check boxes on the MENQOL. Each item was by hand calculated into a 0-7 score. The average for individual domain was calculated between 0 and 7. The high scores in MENQOL subscales show low QOL. ${ }^{7}$

The growth and initial summary of the psychometric properties of the Menopause-Specific Quality of Life questionnaire (MENQOL) is published in year 1996. Since then, the MENQOL is used as result measure and its translated into many languages like Finnish, Italian, Polish, Danish, Norwegian, Dutch for the Netherlands and Belgium, French for France, Belgium and Canada, Spanish for Spain, Mexico, Puerto Rico and Argentina, and Portuguese for Brazil. All translations have included language and cultural variation issues. A translated version of the MENQOL questionnaire was not suitable for Cantonese speaking Chinese women in mainland China. ${ }^{7}$

The Menopause-Specific Quality of Life instrument was developed as a self-administered condition specific instrument to measure health-related quality of life in middle-aged women in the years instantly outside the onset of menopause, defined as one year with no menstrual cycle. It is designed to have both discriminative and evaluative features to assess the impact of this life event and to evaluate interventions. The item-generation phase of the questionnaire development, resultant in 106 items, reflected dimensions of physical, emotional, sexual, intellectual, sleep and social working, including belongings on working life, which might impact on quality of life after a woman is in menopause. ${ }^{7}$

\section{Aim of the study:}

The aim of this review was to identify quality of life in menopausal women in India with the scale Menopause specific quality of life scale (MENQOL).

\section{Methodology:- \\ Design:}

A systematic review was conducted following the centers for Goggle scholar, PUBMED, Cochrane and science direct database using the keywords assessment, menopause, quality of life, post menopause, India, MENQOL. The time frame of the search was from 2010 to 2020 to focus on instrument MEQOL which is used to measure quality of life. After each database was searched by inclusion, reference of relative database was searched for further use of MENQOL scale and paper reporting. An Internet search was also conducted to retrieve literature not available through usual databases. It was accomplished by combining psychometric terms (i.e., reliability, validity). Using the keywords articles were found on the internet. The following inclusion and exclusion criteria were used.

\section{Menopause Sepecif Quuality Of Life Questioneeaire ${ }^{9}$ :}




\section{MENOPAUSE SPECIFC QUAL ITY OF LIFE QUESTIONNAIRE}

7 POINT LIKERT SCALE

Four domains containing 29 items

1) PHY SICAL containing 16 items as following

1. Flatulence/gas pain (GP)

2. Aching in muscles and joints (AMJ)

3. Feeling tried or worn out (FTWO)

4. Difficulty in sleeping (DS)

5. Aches in back of neck or head (ABNH)

6. Decrease in physical strength (DPS)

7. Decreased stamina (DST)

8. Feeling lack of energy (FLE)

9. Dry skin (DRSK)

10. Weight gain (WG)

11. Increased facial hair (IFH)

12. Change in appearances, texture, or skin tone (CATSK)

13. Feeling bloated (FB)

14. L ow backache (LBA)

15. Frequent urination (FU)

16. Involuntary urination while laughing or coughing (IUWLC)

2) VASOMOTOR containing 3 items

1. Hot flushes (HF)

2. Night sweat (NS)

3. Sweating (SW)

3) PSY CHOSOCIAL containing 7 items

1. Dissatisfaction with personal life (DPL)

2. Feeling anxious or nervous (FAN)

3. Poor memory (PM)

4. Accomplished less than I used to (ALIT)

5. Feeling depressed, down or blue (FDDB)

6. Being impatient with other people (BIOP)

7. Feelings of wanting to be alone (FWBA)

4) SEXUAL containing 3 items

1. Change in sex desire (CSD)

2. Vaginal dryness during intercourse (VDDI)

3. Avoiding intimacy (AI)

\section{Selection criteria:}

\section{Inclusion criteria:}

1. Original search articles

2. study including only Indian population

3. study including MENQOL questionnaire for assessment of quality of life

4. studies including menopausal women, menopausal related quality of life

5. Published articles between 2010 to 2020 


\section{Exclusion criteria:}

1. Unpublished articles

2. Unpublished manuscripts

3. Studies containing no original data.

\section{Search strategy:}

Articles were selected from Google scholar using the key terms assessment, menopause, quality of life, post menopause, India, MENQOL, between the range of year 2010-2020.

Among the 199 articles considering the inclusion and exclusion criteria 16 articles were selected for reviewing.

The articles were searched on Google scholar using the key term Menopause first the outcome was 24,900 articles then key term assessment was added to the search number of articles found was 19,900 after the key term assessment MENQOL key term was added to the search number of articles found was 1,060. Then key term India was added to the search and 235 articles were found then filter of year range between 2010- 2020 were added number of articles found was 199 out of which 16 articles were selected out of which 4 articles wereexcluded because of exclusion criteria of women using hormonal replacement therapy so 12 articles are selected for reviewing.

\section{Search outcome:}

The search resulted in 16 papers using MENQOL questionnaire meeting inclusion as well as exclusion criteria given above out of which 4 articles were excluded because of the exclusion criteria of hormonal replacement therapy 12 articles are selected for review

\section{Reuslt:-}

All of papers taken were quantitative study that described the psychometric property of instrument used that is MENQOL. All these papers were published in between the year 2010-2020 with majority $(n=10)$ cross sectional study remaining two papers are descriptive study and survey study respectively.

MENQOL was identified in 12 papers

The reporting of the review results focuses on evaluating the measures in terms of

1. study population

2. reliability and validity

3. responsiveness

4. quality score of reviewed instruments

Table 1:- showing articles included in the study.

\begin{tabular}{|l|l|l|l|}
\hline AUTHOR & $\begin{array}{l}\text { STUDY } \\
\text { TYPE }\end{array}$ & AIM & CONCLUSION \\
\hline $\begin{array}{l}\text { Sudeshna Ray et al. } \\
\text { (june2012) }\end{array}$ & $\begin{array}{l}\text { Cross sectional } \\
\text { study }\end{array}$ & $\begin{array}{l}\text { To assess the quality of life in } \\
\text { women after menopause in West } \\
\text { Bengal population }\end{array}$ & $\begin{array}{l}\text { Women need better quality of } \\
\text { life beyond their reproductive } \\
\text { age }\end{array}$ \\
\hline $\begin{array}{l}\text { Nivedita Som et al. } \\
\text { (September 2012) }\end{array}$ & $\begin{array}{l}\text { Cross sectional } \\
\text { study }\end{array}$ & $\begin{array}{l}\text { To find out the association of } \\
\text { menopause-specific quality of life } \\
\text { of women with both working } \\
\text { status and duration of } \\
\text { postmenopausal years. }\end{array}$ & $\begin{array}{l}\text { Time of post- menopausal year } \\
\text { has association with quality of } \\
\text { life in post -menopausal women }\end{array}$ \\
\hline $\begin{array}{l}\text { Gayathry Nayak et al. } \\
\text { (Dec 2012) }\end{array}$ & $\begin{array}{l}\text { Cross sectional } \\
\text { study }\end{array}$ & $\begin{array}{l}\text { To study the quality of life related } \\
\text { post- menopausal symptoms }\end{array}$ & $\begin{array}{l}\text { Symptoms vary in women to } \\
\text { understand accurately effective } \\
\text { intervention is necessary }\end{array}$ \\
\hline
\end{tabular}




\begin{tabular}{|c|c|c|c|}
\hline $\begin{array}{l}\text { Poomalar G K et al. } \\
(\text { Jan 2013) }\end{array}$ & $\begin{array}{l}\text { Cross sectional } \\
\text { study }\end{array}$ & $\begin{array}{l}\text { The aim of this study was to } \\
\text { assess the quality of life and the } \\
\text { impact of hormonal changes in } \\
\text { postmenopausal women and to } \\
\text { correlate symptoms with their } \\
\text { duration }\end{array}$ & $\begin{array}{l}\text { Such regional studies can help in } \\
\text { creating awareness and in } \\
\text { educating women on the early } \\
\text { identification of the common } \\
\text { menopausal symptoms }\end{array}$ \\
\hline $\begin{array}{l}\text { Leena Salunkhe et al. } \\
(\text { Jul 2015) }\end{array}$ & $\begin{array}{l}\text { Cross sectional } \\
\text { study }\end{array}$ & $\begin{array}{l}\text { To study the quality of life in } \\
\text { post-menopausal women using } \\
\text { MENQL. }\end{array}$ & $\begin{array}{l}\text { Significant association between } \\
\text { the reproductive years and } \\
\text { demographic factors changes the } \\
\text { score of MENQOL. }\end{array}$ \\
\hline $\begin{array}{l}\text { Somak Majumdar et al. } \\
\text { (December2016) }^{15}\end{array}$ & $\begin{array}{l}\text { Cross sectional } \\
\text { study }\end{array}$ & $\begin{array}{l}\text { To find out the quality of life } \\
\text { among the menopausal women } \\
\text { and associations of menopausal } \\
\text { symptom domains with their } \\
\text { socio- }\end{array}$ & $\begin{array}{l}\text { Quality of life among } \\
\text { menopausal women is affected } \\
\text { by the symptoms of menopause } \\
\text { and measures should be taken for } \\
\text { mitigation of the same. }\end{array}$ \\
\hline $\begin{array}{l}\text { Deepshikha Karma et } \\
\text { al. }(\text { Jan 2018) }\end{array}$ & $\begin{array}{l}\text { Cross sectional } \\
\text { study }\end{array}$ & $\begin{array}{l}\text { To find out association of } \\
\text { menopausal symptom domains } \\
\text { with their socio-demographic } \\
\text { parameters }\end{array}$ & $\begin{array}{l}\text { The most common complaints } \\
\text { were feeling tired, decrease } \\
\text { stamina, changes in appearance, } \\
\text { Sexual life was also affected by } \\
\text { menopause. Keywords }\end{array}$ \\
\hline $\begin{array}{l}\text { Thilagavathy } \\
\text { Ganapathy et al. (June } \\
\text { 2018) }\end{array}$ & $\begin{array}{l}\text { Exploratory } \\
\text { study }\end{array}$ & $\begin{array}{l}\text { To assess the impact of } \\
\text { menopausal symptoms on } \\
\text { women's quality of life }\end{array}$ & $\begin{array}{l}\text { Collected model care would } \\
\text { empower women and will } \\
\text { improve quality of life in their } \\
\text { non reproductive years }\end{array}$ \\
\hline $\begin{array}{l}\text { Sumathi Senthilvel et } \\
\text { al. }(\text { Dec 2018) } \\
{ }^{18}\end{array}$ & $\begin{array}{l}\text { Descriptive } \\
\text { study }\end{array}$ & $\begin{array}{l}\text { To study menopausal related } \\
\text { symptoms and their impact on } \\
\text { quality of life }\end{array}$ & $\begin{array}{l}\text { Creating appropriate awareness } \\
\text { about health education might } \\
\text { reduce the burden among the } \\
\text { women. }\end{array}$ \\
\hline $\begin{array}{l}\text { Rajagopal et al. (April } \\
\text { 2019) }^{19}\end{array}$ & $\begin{array}{l}\text { Cross sectional } \\
\text { study }\end{array}$ & $\begin{array}{l}\text { To assess the quality of life in } \\
\text { menopausal women and evaluate } \\
\text { the depression among them. }\end{array}$ & $\begin{array}{l}\text { Proper education is necessary to } \\
\text { improve quality of life in } \\
\text { menopausal woman. }\end{array}$ \\
\hline $\begin{array}{l}\text { R.Sivapragasam et al. } \\
\text { (October 2019) }^{20}\end{array}$ & $\begin{array}{l}\text { Cross sectional } \\
\text { study }\end{array}$ & $\begin{array}{l}\text { To assess the quality of life in } \\
\text { post-menopausal women. }\end{array}$ & $\begin{array}{l}\text { Menopausal symptoms had } \\
\text { negative effect on quality of life } \\
\text { in women. }\end{array}$ \\
\hline $\begin{array}{l}\text { Navdeep Kaur et al. } \\
\text { (April 2020) }^{21}\end{array}$ & $\begin{array}{l}\text { Cross sectional } \\
\text { study }\end{array}$ & $\begin{array}{l}\text { To assess the impact of } \\
\text { menopausal symptoms on } \\
\text { women's quality of life }\end{array}$ & $\begin{array}{l}\text { Knowledgeable physician and a } \\
\text { sensitive psychosocial } \\
\text { professional would help to } \\
\text { improve the quality of life of } \\
\text { menopausal women. }\end{array}$ \\
\hline
\end{tabular}

Table 2:- Symptoms Of Menopausal Women And Scoring Accordig To Menqol.

\begin{tabular}{|l|l|l|l|l|l|}
\hline Study & Sample no & $\begin{array}{l}\text { Vasomotor } \\
(\text { mean \% })\end{array}$ & $\begin{array}{l}\text { Psychological } \\
(\text { mean \% })\end{array}$ & $\begin{array}{l}\text { Physical } \\
(\text { mean\% })\end{array}$ & $\begin{array}{l}\text { Sexual } \\
(\text { mean \% })\end{array}$ \\
\hline
\end{tabular}




\begin{tabular}{|c|c|c|c|c|}
\hline $\begin{array}{l}\text { Sudeshna et al. } \\
44.4 \% \\
\text { (June 2012) }\end{array}$ & 315 & $55.7 \%$ & $56.7 \%$ & $43.35 \%$ \\
\hline $\begin{array}{l}\text { Nivedita et al. } \\
91.73 \% \\
\text { (Sept 2012) }\end{array}$ & 250 & $57.86 \%$ & $76.54 \%$ & $76.25 \%$ \\
\hline $\begin{array}{l}\text { Gayathry et al. } 2012 \\
25.36 \%\end{array}$ & 209 & $33.36 \%$ & $41 \%$ & $44.81 \%$ \\
\hline $\begin{array}{l}\text { Poomalar et al. } \\
37 \% \\
\text { (Jan2013 }\end{array}$ & 100 & $46 \%$ & $59.14 \%$ & $\mathbf{5 8 . 1 8 \%}$ \\
\hline $\begin{array}{l}\text { Leena et al. } \\
28.97 \% \\
\text { (Jul 2015) }\end{array}$ & 115 & $32.14 \%$ & $27.9 \%$ & $35.1 \%$ \\
\hline $\begin{array}{l}\text { Somak et al. } \\
72.66 \% \\
\text { ( Dec 2016) }\end{array}$ & 100 & $39.66 \%$ & $5.66 \%$ & $55.62 \%$ \\
\hline $\begin{array}{l}\text { Deepshikha et al. } \\
40.26 \% \\
\text { (Jan 2018) }\end{array}$ & 500 & $51.53 \%$ & $52.74 \%$ & $46.58 \%$ \\
\hline $\begin{array}{l}\text { Thilagavathy et al. } \\
26.43 \% \\
\text { (June 2018) }\end{array}$ & 140 & $60.43 \%$ & $39.42 \%$ & $74.56 \%$ \\
\hline $\begin{array}{l}\text { Sumathi et al. } \\
75.56 \% \\
\text { ( Dec 2018) }\end{array}$ & 150 & $66.8 \%$ & $66.92 \%$ & $68.92 \%$ \\
\hline $\begin{array}{l}\text { Rajagopal et al. } \\
41.5 \% \\
\text { (April 2019) }\end{array}$ & 150 & $81 \%$ & $61.51 \%$ & $62.49 \%$ \\
\hline $\begin{array}{l}\text { S. Rajini et a1. } \\
\text { 36.1\% } \\
\text { (October 2019) }\end{array}$ & 72 & $12.56 \%$ & $36.34 \%$ & $47.37 \%$ \\
\hline $\begin{array}{l}\text { Navdeep et al. } \\
46.39 \% \\
\text { (April2020) }\end{array}$ & 155 & $52.01 \%$ & $42.53 \%$ & $63.49 \%$ \\
\hline $\begin{array}{l}\text { RESULT - } \\
43.33 \%\end{array}$ & & $40.96 \%$ & $37.4 \%$ & $56.39 \%$ \\
\hline
\end{tabular}


According to total 12 research papers mentioned above scoring of MENQOL scale which has four domains average is calculated of each domain of each study to calculated further investigation.

In this study how quality of life in women's non reproductive years is affected in Indian population is studied using the MENQOL the comparison of 12 studies are selected the average percentage of each domain of each study is calculated and average is calculated of all the studies which resulted in average percentage of physical domain is greater than the any other domain that is vasomotor, psychological or sexual in Indian population.

\section{Discussion:-}

Quality of life is important in every individual's life span. There are numerous factors which affect the quality of life. Women go through many phases in their life some of these phases are pre-menopause, menopause, postmenopause while going through these phase women go through some physical changes which affect the quality of life. According to MENQOL these changes show some signs and symptoms which are divided into 4 domains 1) vasomotor symptoms 2) psychological 3) physical 4) sexual these symptoms.

Sudeshna Ray et.al (june2012) investigated on population of rural area of West Bengal to assess the quality of life in post-menopausal women and their symptoms using the scale MENQOL and sample size was 315 this study concluded that women need better quality of life beyond their reproductive years. The average percentage of each domain of MENQOL as calculated are $\mathbf{5 5 . 7 \% , 5 6 . 7 \% , 4 3 . 3 5 \% , ~} \mathbf{4 4 . 4 \%}$ that is vasomotor, psychological, physical and sexual respectively. ${ }^{10}$

Nivedita Som et.al (September 2012) did cross sectional study in women belonging to West Bengal, India to find out the association of menopause-specific quality of life of women with both working status and duration of postmenopausal years with sample size of 250 women the average percentage of each domain of MENQOL is calculated that is $\mathbf{5 7 . 8 6 \%}, \mathbf{7 6 . 5 4 \%}, \mathbf{7 6 . 2 5 \%} \mathbf{9 1 . 7 3 \%}$ vasomotor, psychological, physical and sexual respectively. ${ }^{11}$

Gayathry Nayak et.al (Dec 2012) studied on quality of life in post-menopausal women in coastal area of Karnataka. This cross-sectional study was done using the MENOL scale to assess the quality of life in menopausal women with sample size of 209. This study concluded that symptoms widely vary in women population. According the

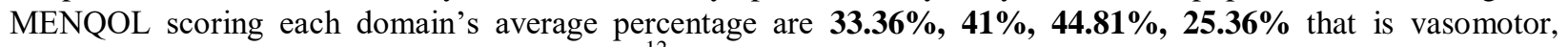
psychological, physical and sexual respectively. ${ }^{12}$

Poomlar GK et.al (Jan 2013) concluded that regional studies may help in creating awareness and in educating women on the early documentation of the common menopausal symptoms by conducting cross sectional study in rural area of Puducherry, India. The aim of this study was to assess the quality of life and the impact of hormonal changes in postmenopausal women and to correlate symptoms with their duration. The sample size selected for it

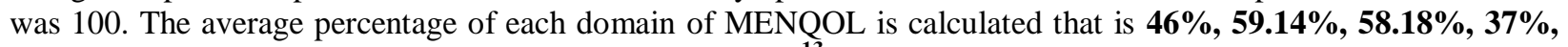
vasomotor, psychological, physical and sexual respectively. ${ }^{13}$

Leena Salunkhe et.al (Jul 2015) conducted hospital based cross sectional study in Manglore to assess the quality of life in post-menopausal women using MENQOL sample size selected was 115 . This study concluded the demographic factors changes the score of MENQOL. The average percentage of each domain of MENQOL calculated is $\mathbf{3 2 . 1 4 \%}, \mathbf{2 7 . 9 \%}, \mathbf{3 5 . 1 \%}, \mathbf{2 8 . 9 7 \%}$ that is vasomotor, psychological, physical and sexual respectively. ${ }^{14}$

Somak Majumdar (December et.al2016) conducted cross sectional study to find out association of menopausal symptom domains with their socio-demographic parameters in slum area of Kolkata, India with sample size of 100 this study concluded that Quality of life among menopausal women is affected by the symptoms of menopause and measures should be taken for mitigation of the same average percentage of each domain of MENQOL is calculated that is $\mathbf{3 9 . 6 6 \%}, \mathbf{5 9 . 6 6 \%}, \mathbf{5 5 . 6 2 \%}, \mathbf{7 2 . 6 6 \%}$ vasomotor, psychological, physical and sexual respectively. ${ }^{15}$

Deepshikha Karma et.al (Jan 2018) investigated in rural area of Punjab find out association of menopausal symptom domains with their socio-demographic parameters with sample size of 500 this study concluded that the most common complaints were feeling tired, decrease stamina, changes in appearance, Sexual life was also affected by

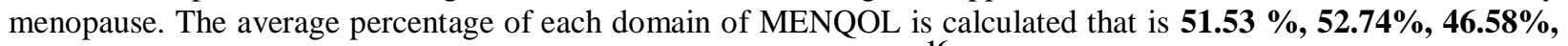
$\mathbf{4 0 . 2 6 \%}$ vasomotor, psychological, physical and sexual respectively. ${ }^{16}$ 
Thilagavathy Ganapathy et.al (June 2018) studied exploratory study in Indian women with sample size of 140 to assess the impact of menopausal symptoms on women's quality of life this study concluded that the Collected model care would empower women and will improve quality of life in their non reproductive years. The average percentage of each domain calculates according to MENQOL is $\mathbf{6 0 . 4 3 \% , 3 9 . 4 2 \% , 7 4 . 5 6 \% , 2 6 . 4 3 \%}$ vasomotor, psychological, physical and sexual respectively. ${ }^{17}$

Sumathi Senthilvel et.al (Dec 2018) conducted descriptive type of study to study menopausal related symptoms and their impact on quality of life in tertiary care hospital in Kochi, India with sample size 150 the average percentage of each domain according to scoring of MEQOL are $\mathbf{6 6 . 8 \%}, \mathbf{6 6 . 9 2} \%, \mathbf{6 8 . 9 2} \% \mathbf{7 5 . 5 6 \%}$ vasomotor, psychological, physical and sexual respectively. ${ }^{18}$

Rajagopal et.al (April 2019) conducted cross-sectional study in Tamilnadu, India to evaluate quality of life in post menopausal women using MENQOL scale with sample size of 150 this study concluded that the proper education is necessary to improve quality of life in post -menopausal women the average score percentage of MENQOL scale considering each domain is $\mathbf{8 1 \%}, \mathbf{6 1 . 5 1 \%}, \mathbf{6 2 . 4 9 \%}, \mathbf{4 1 . 5 \%}$ vasomotor, psychological, physical and sexual respectively. 19

R.Sivapragasam et.al (October 2019) conducted a cross sectional study in rural population of India to assess the quality of life in post-menopausal women from Puduherry using MENQOL scale with sample size of 172 . This study concluded that menopausal symptoms of negative effect on quality of life. The average percentage of this study according to domains of MENQOL are 12.56\%, 36.34\%, 47.37\%, 36.1 vasomotor, psychological, physical and sexual respectively. ${ }^{20}$

Navdeep Kaur et.al(April 2020) conducted a cross sectional study in Indian women population to assess the impact of menopausal symptoms on women's quality of life with sample size 155 the average percentage of each domain according to MENQOL scoring is $\mathbf{5 2 . 0 1 \% , 4 2 . 5 3 \% , 6 3 . 4 9 \% , ~ 4 6 . 3 9 \% ~ v a s o m o t o r , ~ p s y c h o l o g i c a l , ~ p h y s i c a l ~ a n d ~}$ sexual respectively. ${ }^{21}$

All the above studies helped to conclude the result of this study.

\section{Conclusion:-}

After comparing the study done by respective authors it is concluded that physical symptoms are more affected than vasomotor, psychological or sexual in Indian population.

Proper education about the menopause and signs and symptoms is useful to improve quality of life in postmenopausal women.

\section{References:-}

1. https://www.menopause.org/

2. Kalarhoudi MA, Taebi M, Sadat Z, Saberi FA. Assessment of quality of life in menopausal periods: a population study in kashan, iran. Iranian Red Crescent Medical Journal. 2011 Nov;13(11):811.

3. Greendale GA, Lee NP, Arriola ER. The menopause. The Lancet. 1999 Feb 13;353(9152):571-80.

4. https://www.womenshealth.gov/menopause/menopause-symptoms-and-relief

5. https://www.acog.org/patient-resources/faqs/womens-health/the-menopause-years

6. https://my.clevelandclinic.org/health/diseases/15224-menopause-perimenopause-andpostmenopause\#: :text=Perimenopause \%20is\%20the\%20first $\% 20$ stage,is $\% 20$ the $\% 20$ stage $\% 20$ after $\% 20$ menop ause.\&text=As\%20you \%20age\%2C\%20your\%20hormone $\% 20$ levels\%20drop.

7. Shobeiri F, Jenabi E, Hazavehei SM, Roshanaei G. Quality of life in postmenopausal women in Iran: a population-based study. Journal of menopausal medicine. 2016 Apr 1;22(1):31-8.

8. Palacios S, Borrego RS, Forteza A. The importance of preventive health care in post-menopausal women. Maturitas. 2005 Nov 15;52:53-60.

9. Radtke JV, Terhorst L, Cohen SM. The Menopause-Specific Quality of Life (MENQOL) questionnaire: psychometric evaluation among breast cancer survivors. Menopause (New York, NY). 2011 Mar;18(3):289. 
10. Ray S, Dasgupta A. An assessment of QOL and its determining factors of post-menopausal women in a rural area of West Bengal, India: A multivariate analysis. International Journal of Medicine and Public Health. 2012;2(4).

11. Som N, Ray S. Menopause-specific quality of life of urban women in West Bengal, India. Menopause international. 2012 Sep;18(3):99-105.

12. Nayak G, Kamath A, Kumar P, Rao A. A study of quality of life among perimenopausal women in selected coastal areas of Karnataka, India. Journal of mid-life health. 2012 Jul;3(2):71

13. Poomalar GK, Arounassalame B. The quality of life during and after menopause among rural women. Journal of clinical and diagnostic research: JCDR. 2013 Jan;7(1):135

14. Salunkhe L, Rao J. Assessment of Quality of Life and Associated Factors amongst Menopausal Women in DK: A Hospital Based Study.

15. Majumdar S, Dasgupta A. Quality of life among menopausal women-is it still an enigma?. Indian Journal of Community Health. 2016 Oct 1;28(4).

16. Karma D, Saini S, Singh S. Quality of life among post-menopausal women in rural area of Punjab.

17. Ganapathy T, Al Furaikh SS. Health-related quality of life among menopausal women. Archives of Medicine and Health Sciences. 2018 Jan 1;6(1):16.

18. Senthilvel S, Senthilvel Vasudevan PS, Sukumaran A, Sureshbabu J. Assessment of symptoms and quality of life among postmenopausal women in a tertiary care hospital in Kochi, South India: A hospital-based descriptive study. Journal of Mid-life Health. 2018 Oct;9(4):185.

19. Shukla R, Ganjiwale J, Patel R. Prevalence of postmenopausal symptoms, its effect on quality of life and coping in rural couple. Journal of mid-life health. $2018 \mathrm{Jan} ; 9(1): 14$.

20. Sivapragasam R, Rajini S, Rajalakshmi S, Priyanga K, Rajesh V, Priyadharshini R. A community-based crosssectional study about the quality of life in postmenopausal women in rural Puducherry. Indian Journal of Community Medicine. 2020 Jan 1;45(1):96

21. Kaur N, Kaur R. Impact of menopause on quality of life among Indian women life: International Journal of Health and Life-Sciences. 2020 Apr 22;6(1). 